\title{
SSR Analysis of Genetic Diversity and Cold Tolerance in Temperate Rice Germplasm
}

\author{
Jung-Pil Suh ${ }^{1}$, Young-Chan Cho ${ }^{1}$, Jeong-Heui Lee ${ }^{1}$, Sang-Bok Lee ${ }^{1}$,Jae-Youn Jung ${ }^{2}$, Im-Soo Choi ${ }^{1}$, Myeong-Ki Kim ${ }^{1}$, \\ Chung-Kon Kim ${ }^{1}$, and Kshirod K. Jena* \\ ${ }^{1}$ National Institute of Crop Science, Rural Development Administration, Suwon 441-857, Republic of Korea \\ ${ }^{2}$ Yeungnam University, Gyeongsan, Gyeongbuk, 712-749, Republic of Korea \\ ${ }^{3}$ Plant Breeding, Genetics, and Biotechnology Division, International Rice Research Institute, DAPO Box 7777, Metro Manila, \\ Philippines
}

\begin{abstract}
A total of 23 elite rice cultivars from eight countries were evaluated for cold tolerance using two screening methods at Chuncheon Substation, National Institute of Crop Science (NICS), Republic of Korea. The rice cultivars Jinbu, Mustaqillik, and Avangard showed cold tolerance and high spikelet fertility (63-79\%) in cold-water irrigation screening. Under greenhouse screening, five cultivars (Giza 177, Avangard, Mustaqillik, Jinbu, and Jungan) showed high cold tolerance and high spikelet fertility (71-81\%). Simple sequence repeat (SSR) marker analysis of 21 genotypes revealed two major clusters, the japonica and indica groups, with a genetic similarity of 0.69. Out of 21 rice cultivars, only four (Giza 178 from Egypt, Attey and Zakha from Bhutan, and Millin from Australia) fell under the indica cluster. The cold-tolerant varieties Jinbu, Mustaqillik, and Avangard were clustered with the japonica group, which had genetic similarity of 0.83 . These varieties are considered as potential germplasm that will help diversify the japonica gene pool for cold-tolerant rice breeding. A one-way linear analysis of variance identified a significant relationship between individual alleles and traits. Three SSR markers were significantly associated with spikelet fertility under cold-water irrigation on chromosomes 1, 2, and 7. Five SSR markers were associated with spikelet fertility under a cool-environment greenhouse on chromosomes 8, 9, 10, and 12. The SSR markers associated with cold tolerance may also be useful as selection markers in indica/japonica cross combinations to improve cold tolerance.
\end{abstract}

Keywords Rice, Cold tolerance, SSR marker, Genetic diversity, Spikelet fertility

\section{INTRODUCTION}

Rice cultivated in the temperate areas of East and Central Asia and in high altitudes is threatened by cold stress at the seedling, reproductive, and ripening stages (Mackill and Lei 1997). Cold stress causes significant yield loss in rice production (Murai et al. 1991; Nagasawa et al. 1994), thus enhancing cold tolerance through the use of a diverse germplasm of japonica rice is a very important objective in rice breeding. Japonica rice is more cold-tolerant than indica rice, and a wide variation in cold tolerance exists within the japonica rice germplasm (Jeong et al. 2000; Mackill and Lei 1997). Cold stress, however, is still a major constraint in rice production in temperate japonica rice cultivation areas because of the occurrence of high spikelet sterility induced by cold stress during meiosis (Lee 2001). To enhance cold tolerance in rice, it is therefore imperative to exchange and evaluate various rice germplasm from temperate rice-growing countries for cold stress at various growth stages in key japonica rice cultivation sites. Elite cold-tolerant rice germplasm also need to be crossed with a diverse set of elite cultivars from each country. However, there are limited genetic resources for the improvement of cold tolerance in temperate japonica rice cultivars. Some tropical japonica (javanica) cultivars have been reported to exhibit cold tolerance; and cold tolerance genes from the

Received May 21, 2013; Revised Jun 22, 2013; Accepted Jun 23, 2013; Published June 30, 2013

*Corresponding author Kshirod K. Jena, k.jena@irri.org, Tel: +63-2-580-5600 
cultivars Silewah, Lambayque 1, and Padi Labou Alumbis have been introduced into many temperate japonica breeding lines (Abe et al. 1989; Glaszmann et al. 1990; Saito et al. 2001). It is then crucial to identify new genetic resources for cold tolerance to enable rice breeders to develop cold-tolerant rice cultivars for temperate regions. One of the projects of the Temperate Rice Research Consortium (TRRC) aims to develop improved breeding lines with cold tolerance and identify genetic characteristics related to cold tolerance through the exchange of elite germplasm among its member countries. It is very important to accurately evaluate and select cold-tolerant germplasm and use these as donor parents in rice breeding to improve cold tolerance. Various methods can be used to create cold injury environments to evaluate cold tolerance at the booting and reproductive stages in rice. However, screening several materials for cold tolerance is difficult, more so in producing reliable results. Therefore, it is necessary to use a reproducible phenotyping method to measure tolerant and sensitive traits under cold stress and apply improved QTL analysis methods to identify effective QTLs for cold tolerance at the reproductive stage. Screening rice genotypes by imposing cold-water irrigation on all growth stages in the field and by controlled air and water temperatures in the greenhouse, which allow correct measurement of traits associated with cold tolerance, is considered a reliable method of phenotyping for cold tolerance (Suh et al. 2010). The use of molecular markers has also made genetic similarity and dissimilarity of complex quantitative traits easier to understand. SSR markers produce a high frequency of polymorphic alleles in rice and are suitable for evaluating genetic diversity among closely related rice cultivars, including japonica rice (Suh et al. 2004). Extensive genetic studies and QTL analysis with DNA markers have been conducted on several mapping populations. QTL analyses have recently revealed that there are numerous QTLs for cold tolerance in the rice genome (Saito et al. 2001; Andaya and Mackill 2003; Xu et al. 2008; Suh et al. 2010; Ye et al. 2010). The objectives of this study are to identify promising cold-tolerant rice cultivars and to characterize the genetic relationship among the coldtolerant japonica rice germplasm provided by the international partners of the TRRC.

\section{MATERIALS AND METHODS}

\section{Plant materials}

A total of 23 rice cultivars submitted by member-countries of the working group for cold tolerance of the TRRC were used in this study for cold tolerance screening (Table 1). Six check cultivars composed of two indicas (IR64 and IR72), two Tongil-types (Milyang23 and Satbyeol), and two traditional Korean cultivars (Cheonwondo and Migwang) were also used in genetic diversity analysis.

Table 1. List of rice cultivars from eight countries used in this study.

\begin{tabular}{|c|c|c|c|c|c|}
\hline Rice cultivars & Subspecies & Origin & Rice cultivars & Subspecies & Origin \\
\hline Jisheng 202 & japonica & China & IR83222-F8-14 & japonica & IRRI \\
\hline Tongjing 29 & japonica & China & IR83222-F8-156 & japonica & IRRI \\
\hline Changbai 9 & japonica & China & Jinbu & japonica & Korea \\
\hline Giza 177 & japonica & Egypt & Jungan & japonica & Korea \\
\hline Giza 178 & indica & Egypt & Sobaeg & japonica & Korea \\
\hline Sakha 101 & japonica & Egypt & Attey & indica & Bhutan \\
\hline Avangard & japonica & Uzbekistan & Paro Dumbja & japonica & Bhutan \\
\hline Istiqbol & japonica & Uzbekistan & Thimphu Dumbja & japonica & Bhutan \\
\hline Mustaqillik & japonica & Uzbekistan & Zakha & indica & Bhutan \\
\hline Severny & japonica & Russia & Amaroo & japonica & Australia \\
\hline Kuban 3 & japonica & Russia & Millin & indica & Australia \\
\hline Liman & japonica & Russia & Total: 23 cultivars & & 8 countries \\
\hline
\end{tabular}




\section{Evaluation of cold tolerance under cold water imigation}

In the summer of 2009 and 2010, 23 rice cultivars from various countries were evaluated under cold stress through cold water $\left(17^{\circ} \mathrm{C}\right)$ irrigation from maximum tillering to ripening stage at the Chuncheon Substation of NICS, RDA, Republic of Korea. The water temperature gradient was set at $17^{\circ} \mathrm{C}$ at the inlet to $24^{\circ} \mathrm{C}$ at the outlet. To screen for cold-tolerant genotypes, cold water was kept at a depth of $5 \mathrm{~cm}$ during the entire period of rice growth from tillering to grain maturity (June 20 to September 20). Eight agronomic traits were investigated: leaf discoloration (1-9), heading delay (days), culm length reduction (\%), number of panicles, spikelets per panicle, seed fertility (\%), panicle exsertion (1-9), and PA (phenotypic acceptability) at maturity (1-9). Phenotypic data on the percentage of spikelet fertility were collected from the first three panicles of five plants at the critical temperature zone in cold-water and normal-water plots. This screening procedure was performed following the method of Suh et al (2010).

\section{Evaluation of cold tolerance under controlled-air-and- water-temperature conditions}

Five seedlings each of the 23 rice cultivars were grown in plastic pots containing pulverized soil on 25 May. Extra tillers were removed from each plant, leaving just the main tiller to avoid overcrowding and to promote better growth. Three healthy plants showing uniform development stage were selected from each pot; one tiller from each of the three plants was tagged. The plants were then moved to the controlled-air-and-water-temperature greenhouse, maintained at $17^{\circ} \mathrm{C}$, when the auricle of the flag leaf was approximately $4 \mathrm{~cm}$ inside the penultimate leaf of the tillers. After 10 days of cold treatment, the plants were taken back to the normal greenhouse and grown until maturity. The tillers bearing the tag were harvested at maturity and the average number of fertile grains (\%) was measured. Screening using controlled cool-environment greenhouse conditions was performed following the method of Suh et al (2010).

\section{SSR marker and statistical analysis}

The 23 rice cultivars including six check varieties (composed of two indica, two Tongil-type (indicaljaponica), and two traditional Korean japonica) were used for SSR analysis. Genomic DNA was extracted from the fresh frozen leaves of the rice cultivars by a modified $\mathrm{CTAB}$ method (Rogers and Bendich 1988). Eighty-six SSR markers associated with cold tolerance from previous studies were used in the polymorphism survey. The procedure used in the PCR assay was as described by Suh et al (2009). The PCR products were detected using a $4 \%$ denaturing polyacrylamide gel electrophoresis with silver staining. Generated DNA bands were analyzed and scored 1 for the presence- or 0 for the absence of allele. The similarity matrices obtained using the simple matching coefficient were subjected to unweighed pair-group methods using arithmetic average (UPGMA) clustering and represented in dendrogram form using NTSYS-pc program (Rohlf 1993). Linkage association analysis with cold tolerance was performed using ANOVA (one-way analysis of variance) and linear regression from SAS (SAS proc GLM).

\section{RESULTS AND DISCUSSION}

\section{Genetic diversity using SSR markers}

Cluster analysis for the 23 rice cultivars and six check varieties was performed based on similarity coefficient matrices calculated from 86 SSR markers-derived data to generate a dendrogram (Fig. 1). These were grouped into two major clusters, japonica and indica rice, at 0.69 genetic similarity. Four rice varieties (Giza 178 from Egypt, Attey and Zakha from Bhutan, and Millin from Australia) were grouped into the indica cluster. Rice cultivars collected from high-altitude areas of Bhutan were very genetically different from the japonica and indica groups. Two cultivars collected from Bhutan, Paro Dumbja and Thimphu Dumbja, were clustered into the japonica group which had a genetic similarity of 0.76. Except for one variety from Egypt, the japonica rice cultivars collected from China, Egypt, and Korea formed one cluster. Two Korean traditional rice cultivars were included for cluster analysis to trace whether any of the tested cultivars were more similar with them than the others; which resulted to a small subgroup within the japonica group (Fig. 1). 


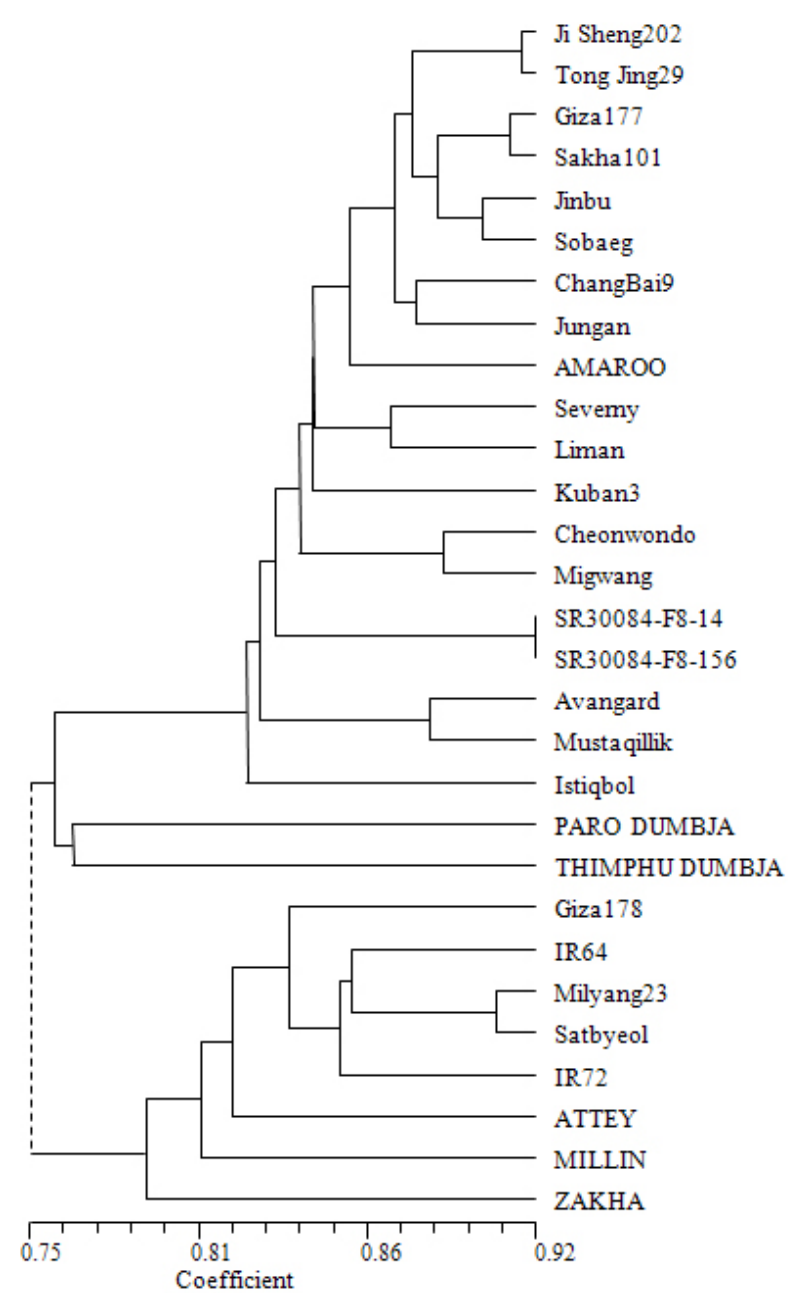

Fig. 1. Dendrogram of 29 collected rice cultivars for cold tolerance, clustered by similarity coefficients using 86 SSR markers.

\section{Cold tolerance of collected rice cultivars under cold water inigation}

Various phenotypic performance responses of the 23 collected rice cultivars screened for cold tolerance were observed as indicated in Table 2. The leaf discoloration ranged from 3 to 8, (mean 5), and spikelet fertility in a cold water-irrigated plot (SFC) ranged from 10 to $79 \%$ (mean $38 \%$ ). Korean japonica rice cultivars showed slightly higher estimates in cold tolerance traits against those of collected cultivars in both screening methods (Table 3). This was the reason Korean rice cultivars were selected to undergo these screening methods with selection criteria for cold tolerance that includes high spikelet fertility and leaf discoloration. Leaf discoloration was at 4-5 degrees in most varieties, 3 degrees in two (IR83222-F8-14 and Sobaeg), and 7-8 degrees in four (Attey, Paro Dumbja, Zakha, and Millin). No leaf discoloration was observed in most japonica rice cultivars, while severe discoloration was observed among the indica rice germplasm. Giza 178, clustered into the indica group, showed moderate cold tolerance and leaf discoloration; Paro Dumbja, clustered into the japonica group, showed a sensitive response. Attey, Zakha, Millin, and Giza 178 were included in the indica group for SSR analysis and showed typically susceptible phenotypes in leaf discoloration under cold water stress. Results show a significant difference in cold tolerance between indica and japonica rice at the seedling stage. It has been reported that

Table 2. Differences in morpho-agronomic traits of 23 rice cultivars under cold stress condition.

\begin{tabular}{lcc}
\hline \hline \multicolumn{1}{c}{ Traits } & Mean $\pm \mathrm{SD}$ & Range \\
\hline Leaf discoloration (1-9) & $5 \pm 1.51$ & $3 \sim 8$ \\
Heading delay (days) & $12 \pm 6.16$ & $5 \sim 23$ \\
Culm reduction (\%) & $22 \pm 9.14$ & $12 \sim 45$ \\
Number of panicle per plant & $14 \pm 2.53$ & $10 \sim 18$ \\
Number of spikelet per panicle & $114 \pm 29.39$ & $76 \sim 177$ \\
Panicle exsertion (1-9) & $4 \pm 1.56$ & $1 \sim 7$ \\
PA-maturity $^{\text {z) }}(1-9)$ & $6 \pm 1.95$ & $1 \sim 8$ \\
$\mathrm{SFC}^{\mathrm{y})}(\%)$ & $38 \pm 19.91$ & $10 \sim 79$ \\
$\mathrm{SFG}^{\mathrm{x})}(\%)$ & $59 \pm 14.33$ & $21 \sim 81$ \\
\hline
\end{tabular}

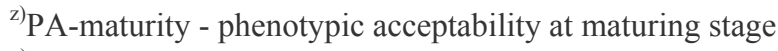

${ }^{\mathrm{y}} \mathrm{SFC}$ - spikelet fertility in cold-water irrigation plot

${ }^{\mathrm{x})} \mathrm{SFG}$ - spikelet fertility in controlled cool-air environment greenhouse 
indica rice tends to show less cold tolerance at the seedling stage (Mackill and Lei 1997). Although Paro Dumbja and Thimphu Dumbja belong to the japonica group, both showed severe leaf discoloration under cold water stress. Despite their affinity to japonica group, Paro Dumbja and Thimphu Dumbja were genetically very different from the other japonica rice cultivars. Indeed, genetic and phenotypic analysis revealed these two to be somewhat intermediate between temperate japonica and indica cultivars. Attey,
Paro Dumbja, and Thimphu Dumbja were not investigated further for cold tolerance and agronomic traits because they did not flower under the environmental conditions of Korea (Tables 3 and 4).

Heading delays in cold-water treatment were less than 10 days in 13 varieties and 16-23 days in seven varieties. Three varieties, Attey, Paro Dumbja (white), and Thimphu Dumbja did not head in cold-water treatment. Culm length decreased by $20 \%$ in 11 varieties and by more than $30 \%$ in

Table 3. Genotypic differences in agronomic traits of collected rice germplasm under cold-water irrigation and controlled air/water conditions. All phenotypic data are mean values from 2009 and 2010 data.

\begin{tabular}{|c|c|c|c|c|c|c|c|c|c|c|}
\hline \multirow{2}{*}{$\begin{array}{l}\text { Rice } \\
\text { cultivars }\end{array}$} & \multicolumn{8}{|c|}{ Cold-water irrigation $^{\text {z) }}$} & \multirow[b]{2}{*}{$\begin{array}{c}\mathrm{SFG}^{\mathrm{y})} \\
(\%) \\
\end{array}$} & \multirow[b]{2}{*}{$\begin{array}{l}\mathrm{M}^{\mathrm{X})} \\
(\%) \\
\end{array}$} \\
\hline & $\begin{array}{l}\text { LD } \\
(1-9)\end{array}$ & $\begin{array}{c}\text { HD } \\
\text { (days) }\end{array}$ & $\begin{array}{l}\text { CR } \\
(\%)\end{array}$ & PN & NSP & $\begin{array}{l}\text { PE } \\
(1-9)\end{array}$ & $\begin{array}{l}\text { PAM } \\
(1-9)\end{array}$ & $\begin{array}{l}\mathrm{SFC} \\
(\%)\end{array}$ & & \\
\hline Jisheng 202 & 6 & 8 & 18 & 11 & 152 & 4 & 7 & 34 & 53 & 44 \\
\hline Tongjing 29 & 4 & 7 & 20 & 17 & 121 & 1 & 8 & 27 & 61 & 44 \\
\hline Changbai 9 & 5 & 9 & 15 & 13 & 130 & 3 & 7 & 17 & 52 & 35 \\
\hline Giza 177 & 4 & 20 & 27 & 14 & 77 & 6 & 7 & 12 & 76 & 44 \\
\hline Giza 178 & 5 & 23 & 45 & 16 & 96 & 7 & 7 & 40 & 21 & 31 \\
\hline Sakha 101 & 3 & 17 & 22 & 17 & 76 & 7 & 9 & 10 & 54 & 32 \\
\hline Avangard & 5 & 8 & 14 & 11 & 106 & 4 & 3 & 63 & 77 & 70 \\
\hline Istiqbol & 5 & 7 & 16 & 10 & 144 & 3 & 5 & 58 & 57 & 58 \\
\hline Mustaqillik & 5 & 5 & 15 & 11 & 82 & 4 & 3 & 69 & 72 & 70 \\
\hline Severny & 6 & 6 & 12 & 10 & 163 & 3 & 5 & 45 & 52 & 49 \\
\hline Kuban 3 & 6 & 7 & 23 & 15 & 127 & 4 & 8 & 12 & 67 & 40 \\
\hline Liman & 6 & 6 & 12 & 12 & 177 & 4 & 7 & 36 & 55 & 46 \\
\hline IR83222-F -14 & 4 & 22 & 15 & 14 & 105 & 3 & 5 & 32 & 63 & 47 \\
\hline IR83222-F -156 & 5 & 21 & 19 & 13 & 101 & 3 & 4 & 34 & 68 & 51 \\
\hline Jinbu & 4 & 11 & 13 & 14 & 123 & 3 & 1 & 79 & 81 & 80 \\
\hline Jungan & 4 & 12 & 18 & 17 & 92 & 4 & 6 & 46 & 71 & 58 \\
\hline Sobaeg & 4 & 12 & 24 & 14 & 134 & 4 & 6 & 40 & 51 & 46 \\
\hline Attey & 8 & - & - & - & - & - & - & - & - & - \\
\hline Paro Dumbja & 8 & - & - & - & - & - & - & - & - & - \\
\hline Thimphu Dumbja & 7 & - & - & - & - & - & - & - & - & - \\
\hline Zakha & 8 & 20 & 33 & 17 & 84 & 5 & 5 & 59 & 45 & 52 \\
\hline Amaroo & 5 & 11 & 36 & 14 & 85 & 6 & 8 & 18 & 56 & 37 \\
\hline Millin & 8 & 16 & 34 & 18 & 108 & 7 & 8 & 25 & 38 & 31 \\
\hline
\end{tabular}

${ }^{2)}$ LD - leaf discoloration, HD - heading delay, CR - culm reduction, PN - number of panicle per plant, NSP - number of spikelet per panicle, PE - panicle exsertion, PAM - phenotypic acceptability at maturing stage, SFC - spikelet fertility in cold-water irrigation plot

${ }^{\mathrm{y}} \mathrm{SFG}$ - spikelet fertility in controlled cool-air environment greenhouse

${ }^{\mathrm{x})} \mathrm{M}$ - mean value of SFC and SFG 
4 varieties. Four varieties (Changbai 9, Giza 177, Kuban 3, and Amaroo) showed less than $20 \%$ of spikelet fertility from the cold-water irrigation screening. These cultivars showed a lower level of spikelet fertility due to cold stress than did indica cultivars tested in this study, which suggests that these cultivars are very susceptible to cold stress at a particular stage, such as the reproductive stage. Three varieties (Avangard, Mustaqillik, and Jinbu) showed more than 63\% of spikelet fertility after cold-water treatment (inlet) in both 2009 and 2010. These varieties were also found to have 1-3 degrees of phenotypic acceptability at the ripening stage. Based on these results Avangard, Mustaqillik, and Jinbu are useful in the development of a cold-tolerant rice variety.

\section{Cold tolerance of collected rice cultivars under controlled- air-and-water-temperature greenhouse}

Five varieties (Giza 177 from Egypt, Avangard and Mustaqillik from Uzbekistan, and Jinbu and Jungan from Korea) had more than $71 \%$ spikelet fertility in a greenhouse with controlled air and water temperature. Giza 178, Zakha, and Millin were grouped as indica rice and proved to be highly susceptible to cold under these conditions. Three rice cultivars (Jinbu from Korea, and Avangard and Mustaqillik from Uzbekistan) showed stable cold tolerance from both screening methods. Avangard and Mustaqillik were of a taller plant type than other japonica rice cultivars, but most agronomic traits are adaptable to japonica rice breeding in

Table 4. Agronomic traits of collected cold-tolerant rice accessions under natural conditions at Chuncheon, Republic of Korea.

\begin{tabular}{|c|c|c|c|c|c|c|}
\hline Rice accessions & $\begin{array}{l}\mathrm{DTH}^{\mathrm{z})} \\
\text { (M.D) }\end{array}$ & $\begin{array}{c}\mathrm{CL} \\
(\mathrm{cm})\end{array}$ & $\begin{array}{c}\mathrm{PL} \\
(\mathrm{cm})\end{array}$ & $\mathrm{PN}$ & NSP & $\begin{array}{l}\text { Fer } \\
(\%)\end{array}$ \\
\hline Ji Sheng 202 & 7.25 & 78 & 21 & 14 & 145 & 96 \\
\hline Tong Jing 29 & 7.24 & 80 & 22 & 13 & 123 & 97 \\
\hline Chang Bai 9 & 7.23 & 77 & 19 & 11 & 139 & 95 \\
\hline Giza 177 & 8.8 & 74 & 19 & 13 & 84 & 95 \\
\hline Giza 178 & 8.17 & 66 & 24 & 15 & 137 & 94 \\
\hline Sakha 101 & 9.6 & 54 & 20 & 13 & 129 & 87 \\
\hline Avangard & 8.5 & 102 & 23 & 10 & 87 & 97 \\
\hline Istiqbol & 8.7 & 114 & 23 & 7 & 140 & 88 \\
\hline Mustaqillik & 8.11 & 99 & 23 & 11 & 71 & 95 \\
\hline Severny & 7.24 & 87 & 17 & 10 & 182 & 95 \\
\hline Kuban 3 & 7.18 & 90 & 21 & 10 & 130 & 96 \\
\hline Liman & 7.25 & 83 & 17 & 11 & 164 & 83 \\
\hline SR30084-F8-14 & 8.25 & 86 & 23 & 10 & 107 & 96 \\
\hline SR30084-F8-156 & 8.9 & 86 & 21 & 10 & 88 & 90 \\
\hline Jinbu & 7.30 & 79 & 19 & 15 & 108 & 98 \\
\hline Jungan & 8.13 & 87 & 20 & 14 & 84 & 96 \\
\hline Sobaeg & 7.29 & 75 & 21 & 12 & 107 & 96 \\
\hline Attey & - & - & - & - & - & - \\
\hline Paro Dumbja & - & - & - & - & - & - \\
\hline Thimphu Dumbja & - & - & - & - & - & - \\
\hline Zakha & 8.30 & 114 & 28 & 13 & 75 & 97 \\
\hline Amaroo & 8.25 & 81 & 20 & 11 & 97 & 94 \\
\hline Millin & 8.7 & 74 & 24 & 13 & 99 & 81 \\
\hline
\end{tabular}

${ }^{2)}$ DTH - days to heading, CL - culm length, PL - panicle length, PN - number of panicle per plant, NSP - number of spikelet per panicle, Fer - spikelet fertility 
the environmental condition of Korea (Table 4). These cultivars can be used as germplasm resource for improving cold tolerance during reproductive stage to sustain high spikelet fertility in japonica rice.

\section{SSR markers associated with spikelet fertility under cold stress}

The japonica sources of cold tolerance, IR66160-1214-4-2, Jinbu, Silewah, Kunmingxizobaigu, and M202, were suitable for temperate japonica breeding or QTL mapping (Andaya and Mackill 2003; Kuroki et al. 2007; Takeuchi et al. 2001; Xu et al. 2008; Suh et al. 2010). Identification of new sources of cold tolerance, followed by the development of appropriate DNA markers associated with a cold tolerance phenotype for spikelet fertility, is an important breeding strategy in improving japonica cultivars at the temperate regions and high-altitude areas of the tropics (Suh et al. 2010). One-way and linear analysis of variance was conducted to identify significance in the relationship between individual alleles and traits (Table 5). Three SSR markers distributed on chromosomes 1, 2, and 7 were significantly associated with spikelet fertility under cold-water irrigation. Likewise, five SSRs distributed on chromosomes 8, 9, 10, and 12 were found associated with spikelet fertility under cool-air environment greenhouse. QTLs for cold tolerance at the booting and reproductive stages in rice were previously mapped on all of the chromosomes (Saito et al. 2001; Andaya and Mackill 2003; Xu et al. 2008; Suh et al. 2010; Ye et al. 2010). Spikelet fertility may be a critical factor associated with cold tolerance and yield under cold stress. Detection of these QTLs and their transfer into japonica rice cultivars may be valuable for breeders to substantially improve cold tolerance in japonica rice. The SSR markers associated with cold tolerance may be useful as selection markers in japonica cross combinations for improving cold tolerance. The promising cultivars Avangard, Mustaqillik, and Jinbu can be very useful as donors in developing mapping populations for identifying new QTL and improving the japonica breeding lines in cold tolerance research.

\section{CONCLUSIONS}

This study identified new sources of germplasm for improvement of cold tolerance in japonica rice. Of 23 cultivars used, three cultivars showed cold tolerance with high spikelet fertility in cold-water screening in the field, while five cultivars showed cold tolerance in cold-airand-water treatment. Genetic diversity analysis using SSR markers grouped the germplasm into japonica and indica types. The number of SSR markers associated with spikelet fertility was three (located on chromosome 1,2, and 7) under cold-water irrigation, and five (located on chromosome $8,9,10$ and 12) under cold-air temperature stress. The three cold-tolerant cultivars identified in this study could be potential sources of germplasm to broaden the gene pool of japonica rice.

Table 5. SSR markers associated with spikelet fertility for cold tolerance.

\begin{tabular}{ccccc}
\hline \hline Traits & Linked SSR marker & Chr. & F-value & No. of alleles \\
\hline SFC $^{\mathrm{z}}$ & RM3475 & 1 & $7.01^{* *}$ & 7 \\
$(\%)$ & RM5764 & 2 & $9.47^{* *}$ & 2 \\
& RM481 & 7 & $7.63^{* *}$ & 10 \\
\hline SFG $^{\mathrm{y}}$ & $\mathrm{RM} 256$ & 8 & $18.56^{* *}$ & 2 \\
$(\%)$ & $\mathrm{RM} 447$ & 8 & $10.62^{* *}$ & 3 \\
& RM1026 & 9 & $10.14^{* *}$ & 4 \\
& RM590 & 10 & $10.16^{* *}$ & 3 \\
& RM512 & 12 & $10.34^{* *}$ & 3 \\
\hline
\end{tabular}

\footnotetext{
${ }^{\text {z) }} \mathrm{SFC}$ - spikelet fertility in cold-water irrigation plot

${ }^{\mathrm{y})} \mathrm{SFG}$ - spikelet fertility in controlled cool-environment greenhouse

** - significant at 0.01 probabilities
} 


\section{ACKNOWLEDGEMENTS}

This work was supported with a grant from the National Institute of Crop Science (Project No. PJ008529), Rural Development Administration, Republic of Korea, and the Temperate Rice Research Consortium. We thank Ms. Leah Cruz, science editor, IRRI for editing the manuscript.

\section{REFERENCES}

Abe N, Kotaka S, Toriyama K and Kobayashi M. 1989. Development of the "rice Norin-PL8" with high tolerance to cool temperature at the booting stage. Res. Bull. Hokkaido Natl. Agric. Exp. Stn. 152:9-17.

Andaya VC and Mackill DJ. 2003. QTLs conferring cold tolerance at the booting stage of rice using recombinant inbred lines from a japonica $\times$ indica cross. Theor. Appl. Genet. 106:1084-1090.

Glaszmann JC, Kaw RN and Khush GS. 1990. Genetic divergence among cold-tolerant rices (Oryza sativa L.). Euphytica 45:95-104.

Jeong EG, Yea JD, Baek MK, Moon HP, Choi HC, Yoon KM and Ahn SN. 2000. Estimation of critical temperature for traits related to cold tolerance in rice. Korean J. Breeding 32:363-368.

Kuroki M, Saito K, Matsuba S, Yokogami N, Shimizu H, Ando I and Sato Y. 2007. A quantitative trait locus for cold tolerance at the booting stage on rice chromosome 8 . Theor. Appl. Genet. 115:593-600.

Lee MH. 2001. Low temperature tolerance in rice: the Korean experience. In: Increased lowland rice production in the Mekong region, Proceedings of an international workshop held in Vientiane, Laos, pp.109-117.

Mackill DJ and Lei X. 1997. Genetic variation for traits related to temperate adaptation of rice cultivars. Crop Sci. 37:1340-1346.

Murai M, Hirose S, Sato S and Takebe M. 1991. Effects of dwarfing genes from Dee-Geo-Woo-Gen and other varieties on cool temperature tolerance at booting stage in rice. Jpn. J. Breed. 41:241-254.

Nagasawa N, Kawamoto T, Matsunaga K, Sasaki T, Nagato Y and Hinata K. 1994. Cold-temperature sensitive mutants at the booting stage of rice. Breeding Sci. 44:53-57.

Rogers OS and Bendich AJ. 1988. Extraction of DNA from plant tissues. Plant Mol. Biol. Manual A6 1-10.

RohlfFJ. 1993. NTSYS-PC numerical taxonomy and multivariate analysis system. Version 2.0j. Exter. Publ. Setauket, New York.

Saito K, Miura K, Nagano K, Hayano-Saito Y, Araki H and Kato A. 2001. Identification of two closely linked quantitative trait loci for cold tolerance on chromosome 4 of rice and their association with anther length. Theor. Appl. Genet. 103:862-868.

Suh JP, Choi YH, Kim KJ, Cho YC, Kwon SJ, Jeong YP, Jeung JU, Choi IS, Kim YG, Choi HC and Hwang HG. 2004. Genetic diversity and QTLs for grain quality in japonica rice. Korean J. Breed. 36:31-37.

Suh JP, Jeung JU, Lee JI, Choi YH, Yea JD, Virk PS, Mackill DJ and Jena KK. 2010. Identification and analysis of QTLs controlling cold tolerance at the reproductive stage and validation of effective QTLs in cold-tolerant genotypes of rice (Oryza sativa L.). Theor. Appl. Genet. 120:985995.

Suh JP, Roh JH, Cho YC, Han SS, Kim YG and Jena KK. 2009. The Pi40 gene for durable resistance to rice blast and molecular analysis of Pi40-advanced backcross breeding lines. Phytopathology 99:243-250.

Takeuchi Y, Hayasaka H, Chiba B, Tanaka I, Shimano T, Yamagishi M, Nagano K, Sasaki T and Yano M. 2001. Mapping quantitative trait loci controlling cool-temperature tolerance at booting stage in temperate japonica rice. Breed. Sci. 51:191-197.

Xu LM, Zhou L, Zeng YW, Wang FM, Zhang HL, Shen SQ and Li ZC. 2008. Identification and mapping of quantitative trait loci for cold tolerance at the booting stage in a japonica rice near-isogenic line. Plant Sci. 174:340-347.

Ye C, Fukai S, Godwin ID, Koh H, Reinke R, Zhou Y, Lambrides C, Jiang W, Snell P and Redona E. 2010. A QTL controlling low temperature induced spikelet sterility at booting stage in rice. Euphytica 176:291-301. 